\title{
Study of serum ceruloplasmin and zinc in type 2 diabetes mellitus
}

\begin{abstract}
Background and objective: Ceruloplasmin is the major copper-carrying protein in the blood and plays a role in iron metabolism. Zinc is an essential trace element for human health, which activates about 200 enzymes. This study aimed to evaluate the serum ceruloplasmin and zinc and the factor affecting them in type 2 diabetes.

Methods: A case-control study was carried out from November 2018 to June 2019 in collaboration between the biochemistry unit at the College of Medicine and the biochemistry unit at the College of Nursing, Hawler Medical University. The study included 100 type 2 diabetic patients (group 1) and 100 healthy individuals (group 2) to evaluate the serum ceruloplasmin and zinc in both groups.

Results: The mean value of serum ceruloplasmin was significantly $(P<0.001)$ higher in type 2 diabetic patients $(55.9 \pm 1.26 \mathrm{mg} / \mathrm{dL})$ than that of healthy individuals $(36.65 \pm 0.71$ $\mathrm{mg} / \mathrm{dL})$. The mean value of serum zinc was significantly $(P<0.001)$ lower in type 2 diabetic patients $(39.19 \pm 0.46 \mathrm{ug} / \mathrm{dL})$ compared with controls $(65.27 \pm 2.5 \mathrm{ug} / \mathrm{dL})$. There was a significant positive correlation between serum ceruloplasmin and the age of diabetic patients $(P<0.001)$. There was a significant negative correlation between serum ceruloplasmin and serum zinc of diabetic patients $(P<001)$. There was no significant correlation between serum ceruloplasmin and body mass index of diabetic patients $(P=0.928)$.
\end{abstract}

Conclusion: Based on the findings of the present study, we concluded that high serum ceruloplasmin and low zinc were associated with type 2 diabetics.

Keywords: Serum ceruloplasmin; Age; BMI; Zinc; Type 2 diabetes mellitus.

\section{Introduction}

Diabetes mellitus was the $8^{\text {th }}$ leading cause of death, accounting for $4 \%$ (1.5 million) of all deaths under the age of 70 in 2012 globally. The most recent data from WHO revealed that 422 million adults are living with diabetes mellitus. ${ }^{1,2}$ The disease is caused in most cases by a deficiency or complete lack of the hormone insulin, which is produced in the pancreas, or by an inability of the body to respond appropriately to insulin (i.e., insulin resistance). Both conditions can include chronically elevated blood glucose levels, excessive excretion of glucose in the urine, and the accumulation of certain acidic substances in the blood. If not prevented or treated properly, these changes can lead to coma and even death. Other adverse events associated with diabetes include the increased risks of associated complications e.g., heart disease, stroke, kidney failure, accounting for another 2.2 million deaths worldwide. ${ }^{5,6}$ Ceruloplasmin is a circulating blue multicopper oxidase that contains $>95 \%$ of copper in the plasma. Ceruloplasmin is synthesized mainly in the liver as a single chain polypeptide. After incorporating six atoms of copper early in the biosynthetic pathway, it is secreted into the plasma as an a2-glycoprotein. ${ }^{7}$ Ceruloplasmin was first described in 1948. The molecular weight of human ceruloplasmin is reported to be

${ }^{1}$ Department of Nursing, College of Nursing, Hawler Medical University, Erbil, I raq.

2 Department of Basic Sciences, College of Medicine, Hawler Medical University, Erbil, I raq.

* Correspondence: sardarna2007@yahoo.com 
$151 \mathrm{kDa}^{8}$ Its precise biological roles are unknown, but may be related to copper transport, iron metabolism, ${ }^{9}$ and antioxidant defense. $^{9}$ Serum level of ceruloplasmin increases during infection and tissue injury. On the other hand, a decrease of the protein in the plasma is observed in some diseases, such as Wilson's disease. ${ }^{10}$ Hereditary hypoceruloplasminemia and hereditary ceruloplasmin deficiency (HCD). $\mathrm{HCD}$ is an autosomal recessive disease characterized by neurological abnormalities such as progressive cerebral degeneration, complete ceruloplasmin deficiency, and excessive storage of iron in the systemic organs, such as the liver and brain. In many HCD cases, type 2 diabetes is the first symptom, and 5-20 years later, at ages $40-60$ years, the neurological abnormalities occur. ${ }^{10}$ An increase in serum ceruloplasmin levels has also been reported in type 2 diabetes. ${ }^{11}$ However, it has been reported that blood HbAlc levels, duration of type 2 diabetes, patient age, and the presence or absence of diabetes complications are not major factors influencing its increase. ${ }^{12}$ So, the question is what factor increases serum ceruloplasmin in type 2 diabetes? To clarify it, serum ceruloplasmin was measured from a relatively large number of type 2 diabetes patients and confirmed an increase in serum ceruloplasmin levels in type 2 diabetes. Next, it was found that a high blood glucose level is one of the important factors. ${ }^{12}$ Trace elements are accepted as essential substances for optimum human health because of their diverse metabolic characteristics and functions. They serve a variety of catalytic, structural, and regulatory functions in which they interact with macromolecules such as enzymes and pro hormones. ${ }^{13}$ Direct association of minerals, trace elements, and vitamins in the pathogenesis and natural course of both type 1 and 2 diabetes mellitus has been observed in many research studies. An alteration in the metabolism of these minerals and vitami ns has been demonstrated. Some trace elements act as antioxidants; prevent membrane peroxidation while others act directly on glucose metabolism. ${ }^{14}$ Zinc is an essential trace element, is a component of many enzymes, and plays an important role in the maintenance of several tissue functions, including the synthesis, storage, and release of insulin. ${ }^{15}$ Zinc plays an important role in glucose metabolism. It has been found to enhance the effectiveness of insulin in vitro, and it has been postulated that its deficiency may aggravate the insulin resistance in non-insulin dependent diabetes mellitus. ${ }^{16}$ This study aimed to estimate serum zinc and ceruloplasmin levels in type 2 diabetes mellitus compared with that of healthy individuals and identify the inter-relationship among these components in healthy controls and type 2 diabetes mellitus.

\section{Methods}

\section{Subjects and Design of the Study}

This study was conducted over a period of eight months, from the $10^{\text {th }}$ of November 2018 to the $30^{\text {th }}$ of June 2019. The subjects included 100 type 2 diabetic patients (35 men and 65 women) as group 1 , with the mean age of $53.85 \pm 1.171$ years, and 100 healthy volunteers (35 men and 65 women) as group 2 with the mean age of $46.42 \pm 1.17$ years. All the cases in both groups (1 and 2) were non smokers and non alcohol drinkers.

\section{Serum Sampling}

Four to six milliliters of venous blood were withdrawn from each individual using a disposable syringe. The samples were obtained from Layla Qasim center specialized for diabetic patients. The samples after half an hour were centrifuged for 10 minutes at $3000 \mathrm{rpm}$, and the serum was analyzed directly.

\section{Methods}

\section{Estimation of the serum ceruloplasmin}

Ceruloplasmin, ferro-oxidase, catalyzes the oxidation of some polyamines, and its action on p-phenylene diamine is measured as the amount in serum. ${ }^{17}$ 


\section{Estimation of the serum zinc}

Zinc forms with 2-(5-Brom-2-pyridylazo)-5(N-propyl-N-sulfopropylamino)-phenol a red chelate complex. The increase of absorbance can be measured and is proportional to the concentration of total zinc in the sample. ${ }^{4}$

\section{Body mass index (BMI)}

The BMI is defined as the body mass divided by the square of the body height and is universally expressed in units of $\mathrm{kg} / \mathrm{m}^{2}$, resulting from mass in kilograms and height in meters. ${ }^{18}$

\section{Statistical analysis}

The statistical evaluation of the results, including the mean, standard deviation (SD), and standard error of the mean (SE), were calculated using the computer Microsoft office 2007. Student's $t$ test of two independent samples has been used to compare between two means. Pearson correlation coefficient was calculated to assess the strength of correlation between two numerical variables. A $P$ value of less than 0.05 was considered statistically significant. $^{19}$

\section{Results}

Serum ceruloplasmin in type 2 diabetes mellitus and control groups

Table 1 provides the mean serum ceruloplasmin in type 2 diabetic patients and normal groups. The mean \pm SE serum ceruloplasmin was $55.9 \pm 1.26 \mathrm{mg} / \mathrm{dL}$ in the type 2 diabetic patient group. This value was significantly $(P<0.001)$ higher than that obtained in the control group $(36.65 \pm 0.71 \mathrm{mg} / \mathrm{dL})$. Table 2 shows the mean serum zinc in type 2 diabetic patients and normal groups. The mean \pm SE serum zinc was $39.19 \pm 0.46 \mathrm{ug} / \mathrm{dL}$ in the type 2 diabetic patient group. This value was significantly $(P<0.001)$ lower than that obtained in the control group (65.27 \pm 2.5 $\mathrm{ug} / \mathrm{dL}$ ). Table 3 shows a significant positive correlation between serum ceruloplasmin with the age of diabetic patients $(P<0.001)$, while a significant negative correlation between serum ceruloplasmin with serum zinc of diabetic patients $(P<0.001)$.

Table 1: The mean \pm SE of serum ceruloplasmin in normal and type 2 diabetes groups.

\begin{tabular}{lcc}
\hline Groups & Ceruloplasmin (Mean \pm SEM) & $P$ value \\
\hline Type 2 diabetes mellitus & $55.9 \pm 1.26 \mathrm{~m} / \mathrm{dL}$ & $<0.001$ \\
Control & $36.65 \pm 0.71 \mathrm{mg} / \mathrm{dL}$ & \\
\hline
\end{tabular}

Table 2: The mean \pm SE of serum zinc in normal and type 2 diabetes mellitus groups.

\begin{tabular}{lcc}
\hline Groups & Zinc (Mean \pm SEM) & $P$ value \\
\hline Type 2 diabetes mellitus & $39.19 \pm 0.46 \mathrm{ug} / \mathrm{dL}$ & $<0.001$ \\
Control & $65.27 \pm 2.5 \mathrm{ug} / \mathrm{dL}$ & \\
\hline
\end{tabular}

Table 3: The correlation between serum ceruloplasmin with various parameters in type 2 diabetes mellitus.

\begin{tabular}{llcc}
\hline No. & parameters & Pearson's correlation $(\boldsymbol{r})$ & $\boldsymbol{P}$ value \\
\hline $1-$ & Ceruloplasmin - age & 0.383 & $P<0.001$ \\
2- & Ceruloplasmin - zinc & -0.354 & $P<0.001$ \\
3- & Ceruloplasmin - BMI & 0.009 & $P=0.928$ \\
\hline
\end{tabular}




\section{Discussion}

Diabetes mellitus is considered a metabolic disorder that affects carbohydrates, lipids, proteins, vitamins, minerals, and water metabolism. The purpose of this study was to determine serum ceruloplasmin (Cu-transporter plasma protein) and serum zinc as essential micromineral to investigate the effect of the disease upon micromineral metabolism. In recent years, chronic diseases, such as diabetes and hypertension, have been shown to be major causes of death worldwide. ${ }^{20}$ The prevalence of diabetes in developed countries has reached immense proportions, which represent a major public health problem. In the current study, the number of females was found to be more than males in both groups, i.e., in diabetics with complications and diabetics without complications. This finding was consistent with the statement that type 2 diabetes is more common in women. ${ }^{21}$ In the present study, serum ceruloplasmin levels were significantly high in diabetic subjects compared to healthy controls $(P<0.001)$. Similar findings have been found in various other studies. ${ }^{22}$, The raised ceruloplasmin levels found in diabetic subjects in the present study are due to a compensatory mechanism. By keeping $\mathrm{Fe}$ in $\mathrm{Fe}^{3+}$ state, ceruloplasmin prevents it from undergoing the redox cycles necessary to initiate toxic effects. Ceruloplasmin converts $\mathrm{Fe}^{2+}$ into $\mathrm{Fe}^{3+}$ and inhibits Fenton reaction because $\mathrm{Fe}^{+2}$ when oxidize to $\mathrm{Fe}^{+3}$. The free electron causes hydrolysis $\mathrm{H} 2 \mathrm{O} 2$ to $\mathrm{OH}$ and $\mathrm{OH}$ that attack components of the cell and ultimately cause damage to the cell. ${ }^{23}$ Many trace elements are important for human metabolic function. Numerous studies have demonstrated the essential roles of trace elements as chromium, zinc, magnesium, selenium, vanadium, molybdenum, and manganese in insulin action and carbohydrate metabolism. The actual role of these trace elements in the pathogenesis and progress of diabetes is still unclear. ${ }^{24}$ The observed alterations in the status of these elements in diabetics have been attributed to hyperglycemia and increased protein glycosylation seen in this condition. In this study, zinc levels in diabetics were lower than in the control group. This finding was in agreement with the other results, ${ }^{25}$ but this finding was contradictory with the findings of the research. ${ }^{26}$ In the mammalian pancreas, zinc is essential for the correct processing, storage, secretion, and action of insulin in beta ( $\beta$ )-cells. Insulin is stored inside secretory vesicles or granules, where two zinc $\left(\mathrm{Zn}^{++}\right)$ions coordinate six insulin monomers to form the hexameric-structure on which maturated insulin crystals are based. ${ }^{27}$ It is also known that, like most other chronic disorders, diabetes increases the excretion of minerals. Hyperglycemia in diabetes is usually associated with hyperzincuria and increased urinary loss of $\mathrm{Zn}^{++}$, which is responsible for decreases in total body $\mathrm{Zn}^{++} \cdot{ }^{28}$ Zinc has antioxidant properties; thus, it can stabilize macromolecules against radical induced oxidation. Zinc is a component of the important antioxidant enzyme superoxide dismutase (Cu-ZnSOD). Thus, the protection of this antioxidant against free radicals generated in the disease will be diminished. ${ }^{29}$ It is also very important to note that zinc concentration regulates the metabolism of other very important members of the antioxidant defensive system. Vitamin A (an antioxidant) is dependent on adequate zinc level for its release from the storage site in the liver and metabolism. ${ }^{29}$

\section{Conclusion}

The mean serum ceruloplasmin in type 2 diabetic patients was significantly higher than that of healthy individuals. So measurement of serum ceruloplasmin may be used as a complementary biomarker in the diagnosis of diabetic patients. The mean serum zinc in type 2 diabetic patients was significantly lower than that of healthy individuals. So diabetes decreasing essential trace elements that have an important role in metabolism. Based on 
current and experimental studies, it is concluded that elevated serum ceruloplasmin and lowered zinc within its laboratory normal range might be an early and sensitive marker for oxidative stress. It is recommended to determine other microelements in type 2 diabetes mellitus and study of gene expression of ceruloplasmin.

\section{Competing interests}

The authors declare no competing interests.

\section{References}

1. American Diabetes Association. Diagnosis and classification of diabetes mellitus. Diabetes Care 2014; 37:81-90

2. Public Health Agency of Canada. Diabetes in Canada: Facts and figures from a public health perspective. Ottawa; 2011.

3. Powers A C. Diabetes mellitus in: Dennis L, Kasper Eugene Braaunwald, Anthony S Fauci, Stephen L Hauser, Dan L, Longo J, Larry Jamson. Harrisons princeples of internal medicine $16^{\text {th }}$ ed. USA, Mc Graw-Hill 2005. P. 2152-80.

4. Carl A Burits, David E. Bruns. Tietz fundamentals of clinical chemistry and molecular diagnostics. $7^{\text {th }}$ ed. Elsevier; 2015. P. 305-6

5. Kaku K. Pathophysiology of type 2-diabetes mellitus and its treatment policy. JMAJ 2010; 53(1):41-6.

6. Robbins C K, Fausto V, Nelson A, Abul K, Cotran RS, Robbins, S L. Pathologic basis of disease $7^{\text {th }}$ edition. Philadelphia, PA: Saunders; 2005. P. 1194-5.

7. Sreekumari S, Vasudevan DM. Textbook of biochemistry. $4^{\text {th }}$ edition. JAYPEE 2005; 225-6.

8- Samokyszyn VM, Miller DM, Reif DW, Aust D: Inhibition of superoxide and ferritin dependent lipid peroxidation by ceruloplasmin. J Biol Chem 2018; 64:21-6.

9. Song D, Dunaief JL. Retinal iron homeostasis in health and disease. Front Aging Neurosci 2013; $5: 24$.

10. Edwards $\mathrm{CQ}$, Williams DA, Cartwright GE. Hereditar hypoceruloplasminemia. Clin Genet 2009; 15:311-6.

11. Memisogullari R, Bakan E. Levels of ceruloplasmin, transferrin, and lipid peroxidation in the serum of patients with type 2 diabetes mellitus. J Diabetes Complications 2004; 18:1937.

12. Navarro JF, Mora C, Maca M, Garca J. Inflammatory parameters are independently associated with urinary albumin in type 2 diabetes mellitus. Am J Kidney Dis 2003; 42:53-61.
13. Shier D, Lewis $\mathrm{R}$, Jackie Br. Hole's Human Anatomy Fourteenth Edition. New York: McGraw Hill Education; 2016. P. 59.

14. Fleet JC. Zinc, copper, and manganese. In: Stipanuk $\mathrm{MH}$, editor. Biochemical and physiological aspects of human nutrition. New York; Sounders 2000. P. 741-59

15. Carocho M, Ferreira IC. A review on antioxidants, prooxidants and related controversy: natural and synthetic compounds, screening and analysis methodologies and future perspectives. Food Chemical Toxicol 2013; 51:5 -25 .

16. Agte VV, Nagmote RV, Tarwadi KV. Comparative in vitro uptake of zinc by erythrocytes of normal vs. type 2 diabetic individuals and the associated factors. Diabetes Nutr Metab 2004; 17:343-9

17. Ramakrishnan S, Sulochana KN. Manual of medical laboratory techniques. $1^{\text {st }}$ ed. New Dehli, India: JAYPEE. 2012. P. 25-6.

18. Angelantonio E, Bhupathiraju N. Body-mass index and all-cause mortality: Individual participant-data meta-analysis of 239 prospective studies in four continents. Lancet 2016; 388(10046):776-86.

19. Martin Bland. An introduction to medical statistics. $4^{\text {th }}$ ed. OUP Oxford: 2015. P. 120-35.

20. World Health Organization. Diabetes. (Accessed March 24, 2021, at: https://www.who.int/healthtopics/diabetes\#tab=tab_1).

21. American Diabetes Association. Diagnosis and classification of diabetes mellitus. Diabetes Care 2004; 27(1):5-10.

22. Lee MJ, Jung $C H$, Kang YM, Jang JE, Leem J, Park JY, et al. Serum ceruloplasmin level as a predictor for the progression of diabetic nephropathy in Korean men with type 2 diabetes mellitus. Diabetes Metab J 2015; 39(3):230-9.

23. Enomoto $M$, Adachi $H$, Hirai $Y$, Fukami $A$, Satoh A, Otsuka $M$, et al. LDL-C/HDL-C Ratio Predicts Carotid Intima-Media Thickness Progression Better Than HDL-C or LDL-C Alone. J Lipids 2011; 1(1):6-10.

24. Reenu S, Sunil S, Maulik S. Study of impairment in collaboration between ceruloplasmin and transferring in development of complications in type 2 diabetes mellitus. International Journal of Research in Medical Sciences 2016; 4(8):3611 -5 .

25. Zargar A, Bashir M, Masoodi S, Laway B, Wani A, Khan A, et al. Copper, zinc and magnesium levels in type-1 diabetes mellitus. Saudi Med J 2002; 23:539-42.

26. Osman E, Vliyaoglu, Levent K, Nuriye U, Nazife $\mathrm{K}$, Baysal $\mathrm{K}$, et al. Correlation of serum $\mathrm{Cu}^{+2}$, $\mathrm{Zn}^{+2}, \mathrm{Mg}+2$ and $\mathrm{HbA} 1 \mathrm{c}$ in type 1 and type 2 Diabetes Mellitus. Turk $\mathrm{J}$ of Endo and Metab 2004; 8:75-9.

27. Li YV. Zinc and insulin in pancreatic beta-cells. Endocrine 2014; 45:178-89. 
28. Anetor JI, Senjobi A, Ajose OA, Agbedana EO. Decreased serum magnesium and zinc levels: atherogenic implications in type-2 diabetes mellitus in Nigerians. Nutrition and Health 2002; 16:291-300

29. Singh R, Niaz M, Rastogi S. Current zinc intake and risk of diabetes and coronary heart disease and factors associated with insulin resistance in rural and urban population of North India. J Am Coll Nutr 2000; 17:564-70. 